\title{
AMENDMENTS
}

\section{Author Correction: Multiplexed droplet single-cell RNA-sequencing using natural genetic variation}

Hyun Min Kang, Meena Subramaniam, Sasha Targ, Michelle Nguyen, Lenka Maliskova, Elizabeth McCarthy, Eunice Wan, Simon Wong, Lauren Byrnes, Cristina M. Lanata, Rachel E. Gate, Sara Mostafavi, Alexander Marson, Noah Zaitlen,

Lindsey A. Criswell and Chun Jimmie Ye

Correction to: Nature Biotechnology https://doi.org/10.1038/nbt.4042, published online 11 December 2017.

In this article as published, there were errors or omissions in three equations in the Methods. In paragraph 1, in the sentence "When $e_{c v i}=1$, we assume that $\operatorname{Pr}\left(b_{c v i} \mid g, e_{c v i}\right)$ follows Supplementary Table 4," the probability expression should be clarified by the addition of an equivalency: "we assume that

$$
\operatorname{Pr}\left(b_{c v i} \mid g, e_{c v i}\right)=\frac{\operatorname{Pr}\left(b_{c v i}, e_{c v i} \mid g\right)}{\operatorname{Pr}\left(e_{c v i}\right)}
$$

follows Supplementary Table 4."

As published, the equation at the end of paragraph 2 reads

$$
L_{c}(s)=\prod_{v=1}^{V}\left[\sum_{g=0}^{2}\left\{\prod_{i=1}^{d_{c v}}\left(\sum_{e=0}^{1} \operatorname{Pr}\left(b_{c v i} \mid g, e\right)\right) P_{s v}^{(g)}\right\}\right]
$$

The correct equation is

$$
L_{c}(s)=\prod_{v=1}^{V}\left[\sum_{g=0}^{2}\left\{\prod_{i=1}^{d_{c v}}\left(\sum_{e=0}^{1} \operatorname{Pr}\left(b_{c v i}, e_{c v i} \mid g\right)\right) P_{s v}^{(g)}\right\}\right]
$$

At the end of the first paragraph in the second section, the equation as published reads

$$
L_{c}\left(s_{1}, s_{2},\right) \alpha=\prod_{v=1}^{V}\left[\sum_{g_{1}, g_{2}}\left\{\prod_{i=1}^{d_{c v}}\left(\sum_{e=0}^{1}(1-\alpha) \operatorname{Pr}\left(b_{c v i} \mid g_{1}, e\right)+\alpha \operatorname{Pr}\left(b_{c v i} \mid g_{2}, e\right)\right) P_{s v}^{\left(g_{1}\right)} P_{s v}^{\left(g_{2}\right)}\right\}\right]
$$

The correct equation is

$$
L_{c}\left(s_{1}, s_{2}, \alpha\right)=\prod_{v=1}^{V}\left[\sum_{g_{1}, g_{2}}\left\{\prod_{i=1}^{d_{c v}}\left(\sum_{e=0}^{1}(1-\alpha) \operatorname{Pr}\left(b_{c v i}, e \mid g_{1}\right)+\alpha \operatorname{Pr}\left(b_{c v i}, e \mid g_{2}\right)\right) P_{s v}^{\left(g_{1}\right)} P_{s v}^{\left(g_{2}\right)}\right\}\right]
$$

The errors affect the article only, not the implementation of the tool. They have not been corrected in the original article.

Published online: 14 October 2020

https://doi.org/10.1038/s41587-020-0715-9

(c) The Author(s), under exclusive licence to Springer Nature America, Inc. 2020 